\title{
Políticas de salud de impacto ciudadano
}

La Revista Chilena de Salud Pública constituye un escenario propicio para la reflexión y el debate acerca de los temas que hoy en día preocupan a quienes, en distintos roles y posiciones, participan en el diseño e implementación de las políticas públicas de salud. Por ello, en esta oportunidad queremos tocar un aspecto de especial relevancia: el de las respuestas en el ámbito de la participación ciudadana, para enfrentar exitosamente las persistentes desigualdades en el acceso y calidad de los cuidados de salud en nuestro país.

En la actualidad, el mundo enfrenta aceleradas transformaciones, ocupando los avances científicos y tecnológicos un lugar destacadísimo. Desafortunadamente, no podemos decir lo mismo al analizar la escasa consideración de las ciencias sociales y del comportamiento en las diferentes acciones de salud y en el aliviar el dolor humano asociado a la enfermedad, siendo imperioso generar nuevas respuestas a los problemas de salud. Este desafío que adquiere características dramáticas al constatar que más de la mitad de la población mundial vive en condiciones de pobreza y, por lo tanto, no cuenta con atención básica o la que recibe es insuficiente.

En consecuencia, es necesario involucrar y comprometer a las personas y a las organizaciones sociales en el cuidado de su salud, privilegiando el autocuidado, la entrega de información oportuna, y la solidaridad con el vecino. En una frase, empoderando a la ciudadanía. Esto debe traducirse en generar nuevas formas de participación, sustentadas en acuerdos, una especie de pacto social, entre la ciudadanía representada por sus organizaciones y las instituciones del Estado, siendo el municipio quien tiene la mayor responsabilidad en este ámbito.

También es importante reconocer y apropiarse de numerosas experiencias de buenas prácticas en salud, la mayoría efectuada a nivel local, que desafortunadamente no son conocidas ni difundidas como sería de esperar. En parte este rol lo cumple la Escuela de Salud Pública a través de las Jornadas Chilenas de Salud Pública, en que se presentan experiencias llevadas de equipos locales, muchas veces enfrentados a dificultades para obtener adecuada información e insuficientes recursos.

Esta acción social debe ir acompañada de una eficiente gestión participativa y moderna de los servicios de salud, gestión que debe considerar tanto a los usuarios externos, como a los internos, ya que la satisfacción y compromiso de estos últimos es imprescindible para asegurar la calidad de los servicios que requiere la población. Además, deben hacerse serios esfuerzos para que los programas de salud sean evaluados regularmente en términos de su aceptabilidad, impacto y sustentabilidad, considerando dimensiones tan importantes como su cobertura, penetración, efectividad, multisectorialidad y efectiva participación ciudadana.

Una dimensión que en nuestro país generalmente no se considera prioritaria es la formación y capacitación de los recursos humanos, que considere las necesidades actuales, pero tal vez más importante, la formulación de una política consonante con los profundos cambios demográficos y epidemiológicos que está experimentando nuestro país.

Para disponer de una fuerza de trabajo en salud suficiente y apropiada es necesario definir, junto con la política, los recursos humanos que necesita el país, estableciendo programas de formación, capacitación, retención y desvinculación del personal de salud, así como generando proyecciones sobre las necesidades a futuro según tipo, niveles de formación, distribución espacial, etc. Igualmente importante es definir y dimensionar los perfiles de la oferta por parte de las instituciones académicas, las que junto con el desarrollo 
de programas de excelencia se hagan cargo de su responsabilidad social, más allá de intereses particulares.

Otra situación que preocupa es el serio desajuste que existe entre el número de médicos y de otros profesionales y técnicos de salud en nuestro país, con una inadecuada distribución de los primeros y gran déficit de los segundos. Este problema es particularmente serio en atención primaria, donde los médicos trabajan "con taxímetro" atendiendo enfermos y, por lo tanto, están ausentes del trabajo en equipo y de importantes programas de protección en salud, los cuales debieran liderar.

En conclusión, he aquí un conjunto de propuestas que deben ser parte de una política pública de salud que -efectivamente- tenga el impacto ciudadano esperado y, en consecuencia, contribuya a mejorar las condiciones de salud de toda la población chilena. 